\title{
Cracking of the Vault in a Church Building and Activities Undertaken in the View of the Further Mining Exploitation
}

\author{
Marian Kawulok ${ }^{1, *}$, Leszek Chomacki ${ }^{1}$, and Tadeusz Rutkowski ${ }^{2}$ \\ ${ }^{1}$ ITB Building Research Institute, Building Structures, Geotechnics and Concrete Department, \\ 40-153 Katowice al. W. Korfantego 191, Poland \\ ${ }^{2}$ Polska Grupa Górnicza, Oddział KWK Ruda, Ruch Pokój, 41-710 Ruda Śląska, \\ ul. Niedurnego 13, Poland
}

\begin{abstract}
The paper concerns a church building, where as a result of mining exploitation a number of damages have been observed, including cracking of the nave. The method of repairing the damage was presented. Taking into consideration the further planned mining exploitation, a concept was put forward to reinforce the church with steel tie rods at the level of the vaults over the nave, which will provide for its protection against adverse impact of the tilt of the land surface.
\end{abstract}

\section{Introduction}

The sacral buildings constructed in the past, in the mining areas, are subjected to damage resulting from the impact of horizontal movements $(\varepsilon)$ and radius of curvature $(R)$ of the land surface [1-3]. This is implied most of all by the significant size of such buildings and the fact their structure is not suited to taking over additional forces resulting from these impacts.

The paper presents a case in which the main hazard to the church building structure was posed by the tilt of the land surface $(T)$. Also presented are the construction activities undertaken to eliminate or at least reduce the impact of the land tilt on the church building.

\section{Church building structure description}

The church building erected in 1909 has a neo-Gothic body fragmented in both the horizontal and vertical directions (Fig. 1). Its dimensions in plan are ca. $54.0 \mathrm{~m} \times 32.0 \mathrm{~m}$. The main axis of the church runs in the NS direction. The main part of the church body is the nave with a width of ca. $13.4 \mathrm{~m}$ passing in the $\mathrm{N}$ part of the building into the presbytery and two aisles, each with a width of ca. $4.8 \mathrm{~m}$ (Fig. 8). The height of the nave measured from the floor level to the keystone is ca. $18.3 \mathrm{~m}$, while the aisles are approx. $7.7 \mathrm{~m}$ high. At the south side of the church, a tower was erected, with a height of approx. $60 \mathrm{~m}$, together with the main entrance portal.

\footnotetext{
* Corresponding author: m.kawulok@itb.pl
} 


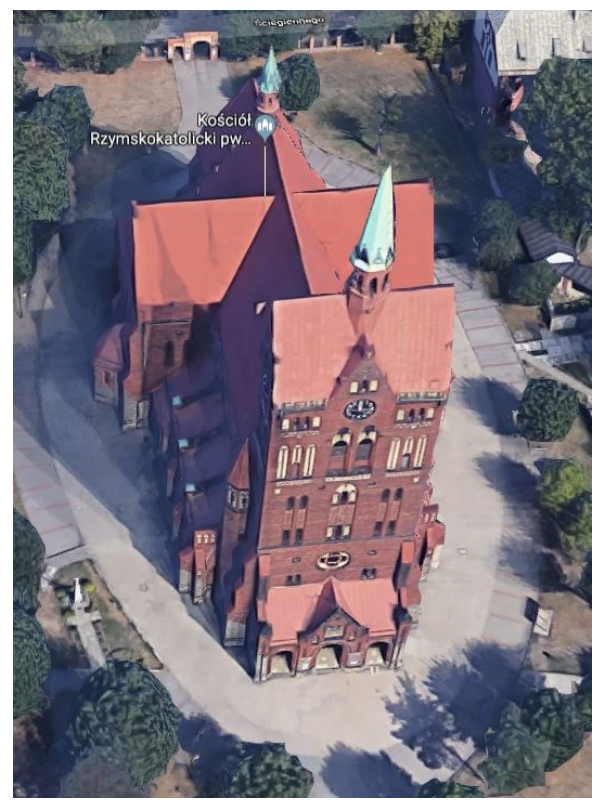

Fig. 1. A satellite photograph showing the church.

The load-bearing system of the church building is made of external brick walls with a thickness of up to approx. $120 \mathrm{~cm}$ and internal brick pillars. The cover of the nave and the aisles are the monastery vaults. In the vestibule of the main entrance, however, a wooden ceiling was made under the organ gallery. The roof was made as a wooden structure and covered with ceramic tiles.

The church was protected against the impact of mining deformations by means of an external reinforced concrete slab to stiffen the church building primarily in the horizontal plane. The slab was constructed in December 1976 and has a form of a perimeter ring with a width of approx. $6.0 \mathrm{~m}$ to approx. $13.0 \mathrm{~m}$. The slab thickness ranges between $30 \mathrm{~cm}$ and $40 \mathrm{~cm}$ and it is reinforced with top and bottom $\varnothing 12$ rebars placed every $25 \mathrm{~cm}$. The structure of the slab was connected with the outer walls of the church by means of $\varnothing 20$ rebars, at the same time increasing its height in the underground part. Following to the impact of shrinkage, the slab was constructed with contraction joints.

\section{Impact of the past mining exploitation and corrective actions}

\subsection{Past mining exploitation}

In the vicinity of the church, since 1930 exploitation was carried out in 22 seams, at a depth of 220 to $800 \mathrm{~m}$, which was carried out with walls between 2.1 and $3.7 \mathrm{~m}$ in height, using systems with a roof caving or with hydraulic backfill.

In the recent years, i.e. 2015-2017, mining was carried out with roof caving at the depth of $540 \mathrm{~m}$. The exploitation was performed in a direction parallel to the longitudinal walls of the church, from the $\mathrm{S}$ towards the $\mathrm{N}$ direction. According to the geodetic survey results [4], the mining exploitation conducted in 2017 caused inclination of the main body of the church building by ca. $T_{b, 1}=6 \mathrm{~mm} / \mathrm{m}$ in the $\mathrm{N}$ direction and the tower by $T_{b, 2}=13 \mathrm{~mm} / \mathrm{m}$ to the $\mathrm{S}$, i.e. in the opposite direction. In addition to the land surface tilting in the church area, horizontal strains occurred that caused loosening of the mining subsoil $\varepsilon=2.5 \mathrm{~mm} / \mathrm{m}$. 


\subsection{Condition of damage to the church after exposure of the impact}

As a result of the different directions of inclination of the church and the tower, in the first vaulted field adjacent to the tower significant cracks shown in figures $2 \mathrm{a}-2 \mathrm{~d}$ occurred.

a)

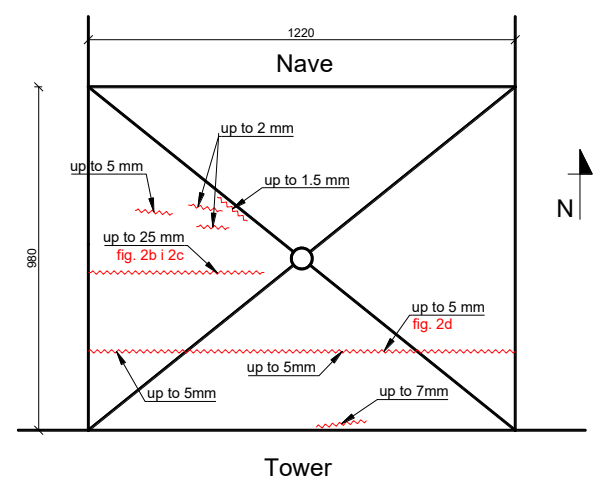

c)

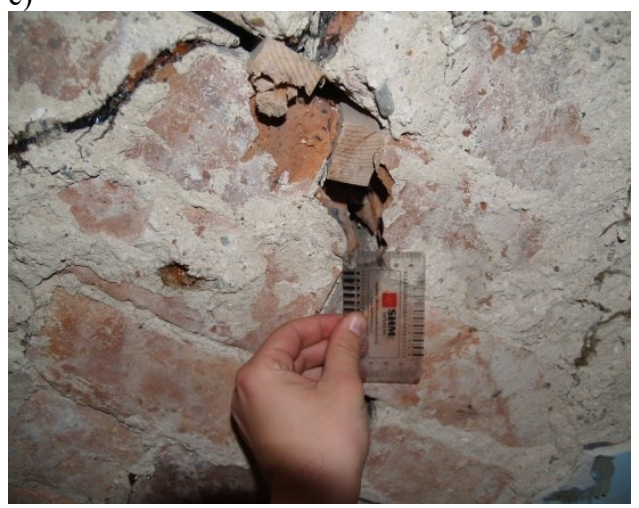

b)

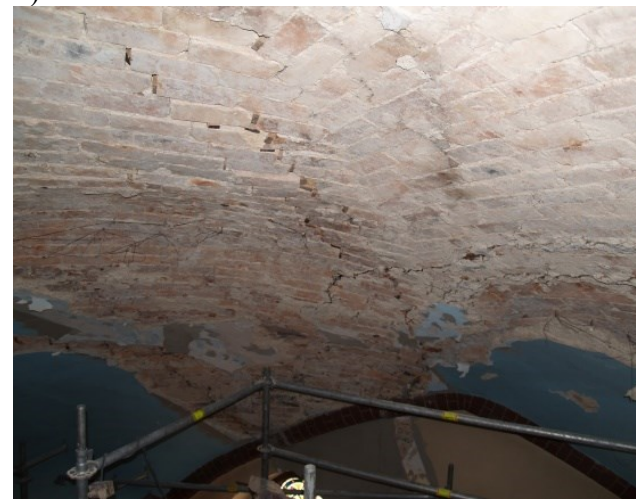

d)

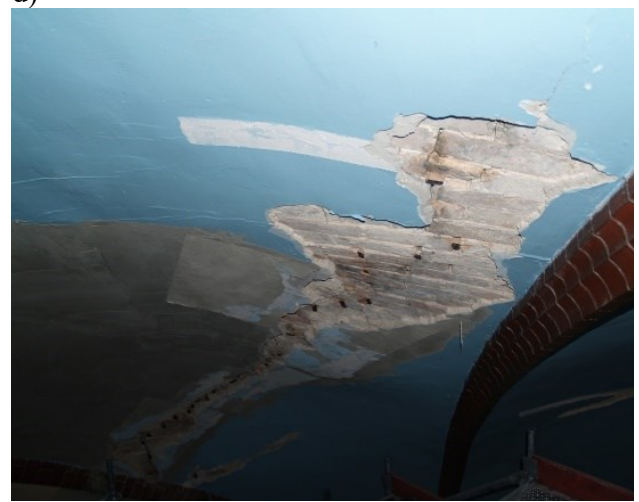

Fig. 2. Inventory of the vault cracks: a) the crack location and aperture width (dimensions in $\mathrm{mm}$ ), b) $\div$ d) a view of the cracks.

In addition to the vault damages, cracking with a width of $20 \mathrm{~mm}$ of the perimeter slab were recorded outside of the church which are visible at the western side of the church building at the location of the expansion gaps (Fig. 3a) as well as cracking of the nave walls (Fig. 3b) in their upper parts (Fig. 3c) and of the aisle walls in their lower parts (Fig. 3d) with a maximum aperture staring also from $20 \mathrm{~mm}$.

Inside the church, damages within the plate traceries (Fig. 4a), cracking of walls, lintels, ribs and arches with an aperture of $4-20 \mathrm{~mm}$ (Figs 4b, 5a, 5b) and cracking at the joint of vaults and ribs have been observed. 
a)

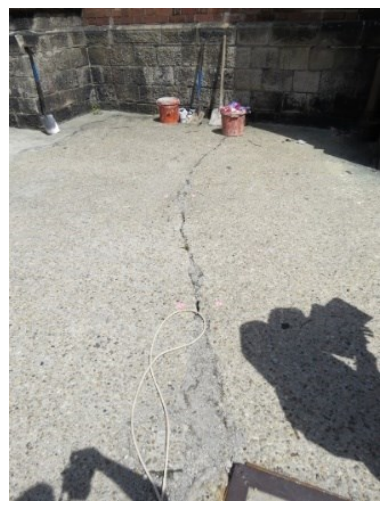

c)

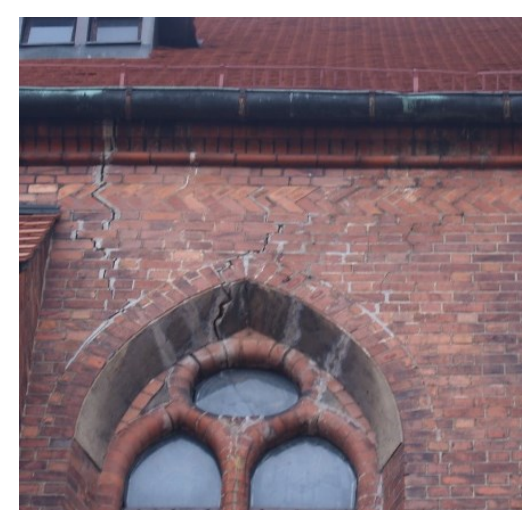

b)

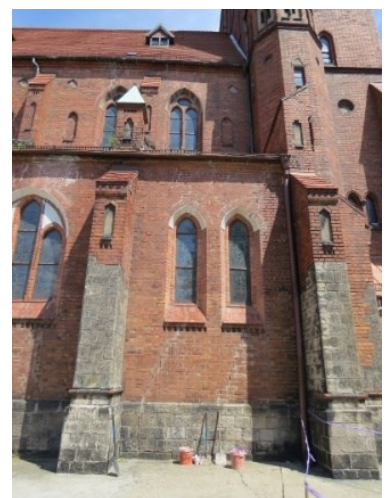

d)

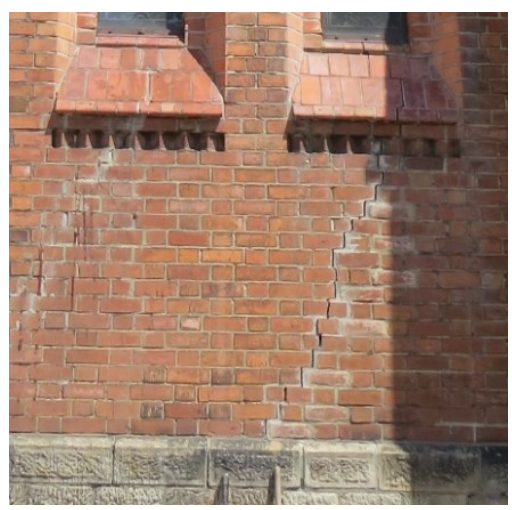

Fig. 3. Examples of damages recorded outside the church: a) cracking of the reinforced concrete slab, b) diagonal cracking of walls, c) walls and lintels of the nave, d) walls of the aisle.

a)

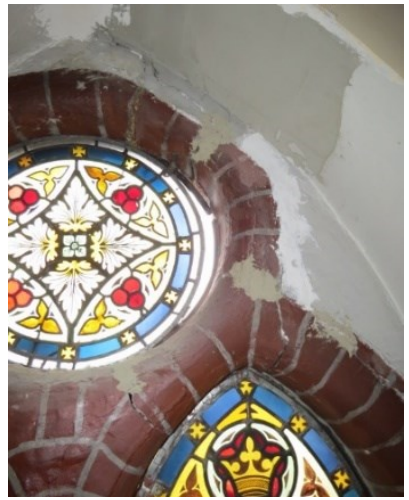

b)

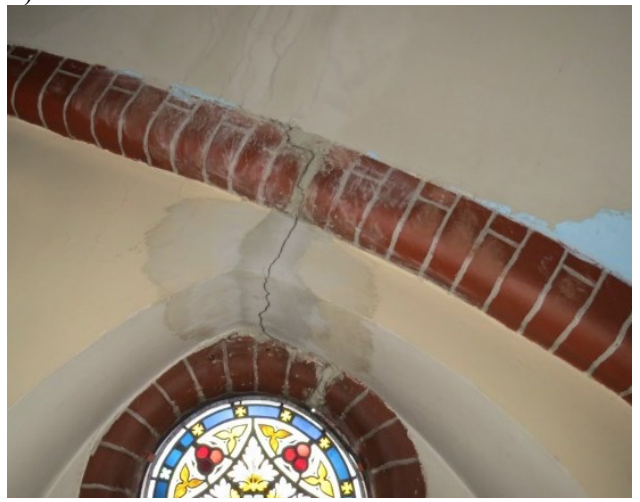

Fig. 4. Examples of damages recorded inside the church: a) cracking of the plate traceries, b) cracking of the lintel. 
a)

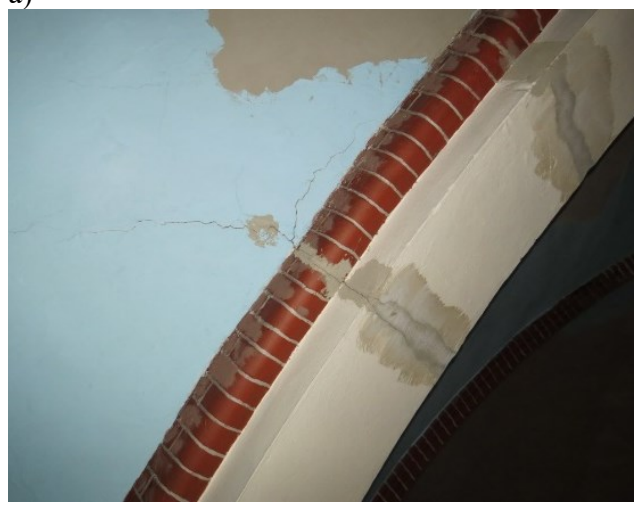

b)

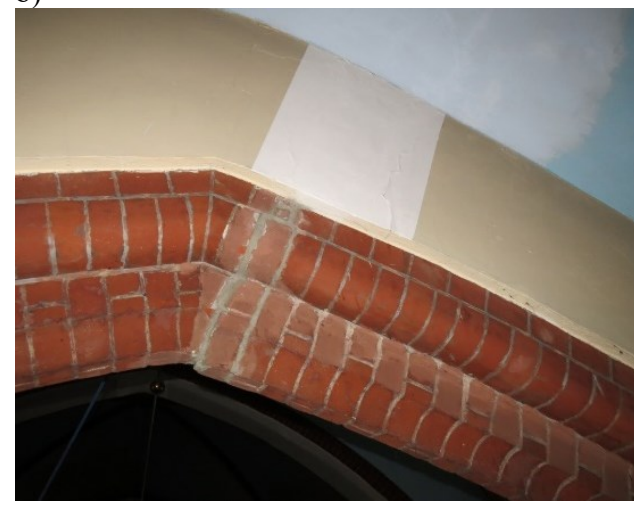

Fig. 5. Examples of damages recorded inside the church: $a-b)$ cracking of ribs and arches.

\subsection{Corrective actions taken}

The corrective actions consisted in the following:

- as a temporary measure oak wedges were installed in the cracked vault,

- injecting from the top of the cracking of the first vaulted field of the nave with a swelling hydraulic cement (cracking with aperture $>5 \mathrm{~mm}$ ) or epoxy resins (cracking with aperture $<5 \mathrm{~mm}$ ),

- from the bottom, the vault was covered with a layer of adhesive, steel and plastic fasteners were used to fix steel mesh to the vault, which was then covered with a layer of adhesive to embed the mesh,

- rebuilding and reinforcing with spiral rebars and two prefabricated ceramic lintels of the cracked eastern wall of the nave from the inside of the church,

- rebuilding and reinforcing with spiral rebars of the cracked western wall of the nave from the inside of the church,

- rebuilding and reinforcing with spiral rebars of a fragment of the western wall of the aisle in the sub-window and lintel section,

- welding of rebars to the ripped bars of the reinforced concrete slab at the western side of the church, after which the hammered-off part of the slab was concreted,

- reinforcing the rib of the vault with a system of carbon fiber meshes according to the scheme shown below (Fig. 6). Fragments of the carbon fiber mesh left after the rib reinforcement were placed on the previously cracked surfaces of spannings.

At the same time, on the initiative of the mine management, a platform was made using the system scaffolding at the level of skewbacks of the vaults (Fig. 7), on the entire area of the church, in order to carry out ongoing repairs of the vaults in the view of planned mining exploitation. 


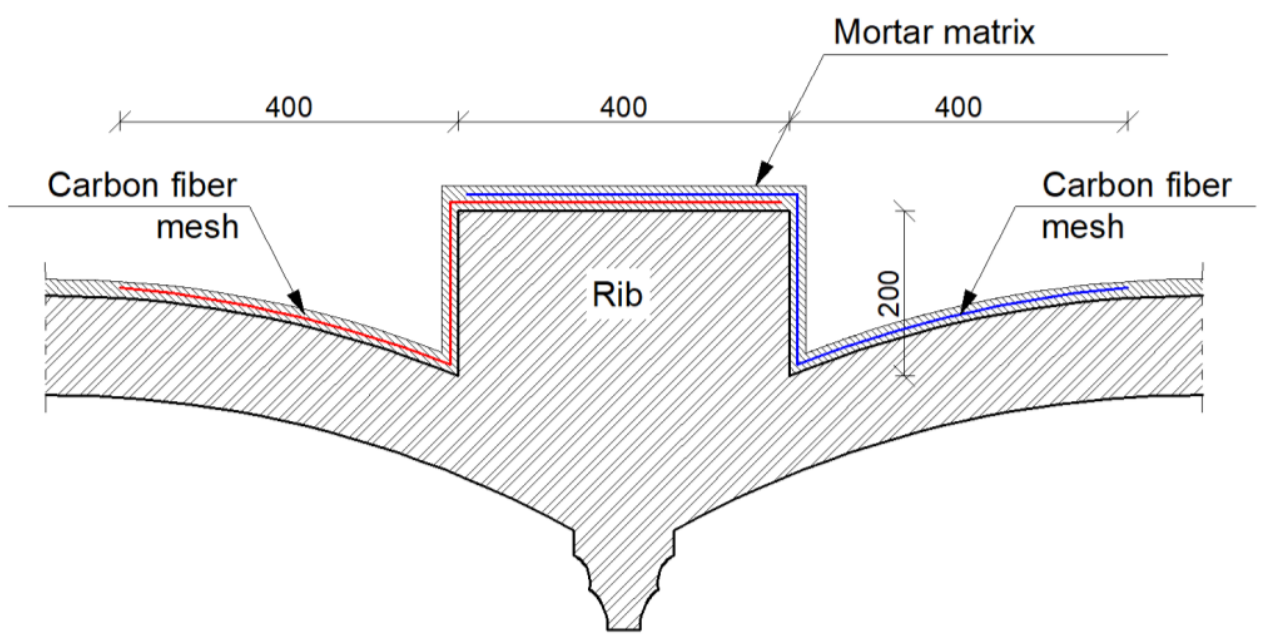

Fig. 6. A scheme of reinforcement of the vault with ribs (dimensions in $\mathrm{mm}$ ).

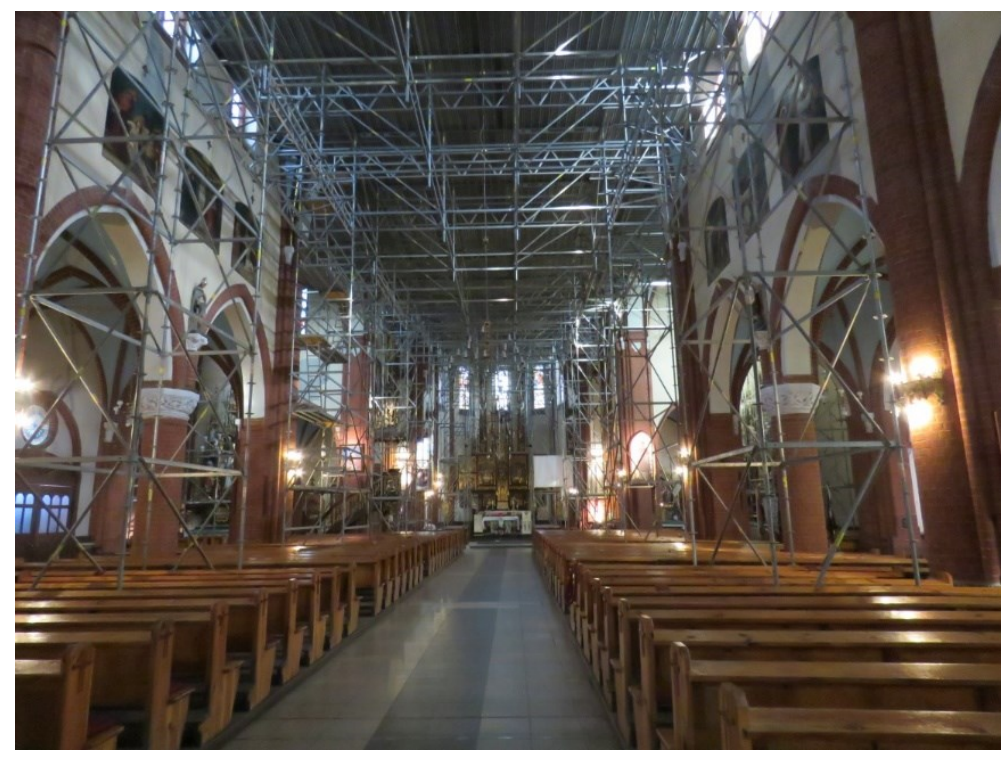

Fig. 7. A view of the bridge at the level of vault headboards.

\section{Impact of the planned mining exploitation and the proposed reinforcement concept}

\subsection{Planned mining exploitation}

The planned mining operations assume passing of the extraction works directly under the church building, almost parallel to its longitudinal axis. The works will be passing, as previously, from south to north.

The predicted values of the extreme and final indicators of land deformation in the vicinity of the church are presented in Table 1. 
Table 1. Values of calculated extreme and final deformation indicators in the church area.

\begin{tabular}{|c|c|c|c|c|c|c|}
\hline $\begin{array}{c}\text { Deformation } \\
\text { indicator }\end{array}$ & subsidence & tilt & horizontal deformation & \multicolumn{2}{|c|}{ radius of curvature } \\
\cline { 2 - 7 } & $w[\mathrm{~m}]$ & $T[\mathrm{~mm} / \mathrm{m}]$ & $\begin{array}{c}\varepsilon \max (+) \\
{[\mathrm{mm} / \mathrm{m}]}\end{array}$ & $\begin{array}{c}\varepsilon \min (-) \\
{[\mathrm{mm} / \mathrm{m}]}\end{array}$ & $\begin{array}{c}R_{\max }(+) \\
{[\mathrm{km}]}\end{array}$ & $\begin{array}{c}R_{\min }(-) \\
{[\mathrm{km}]}\end{array}$ \\
\hline Extreme values & 1.73 & 6.0 & +2.2 & -3.6 & 37 & -22 \\
\hline Final values & 1.73 & 0.5 & +0.7 & -1.5 & 100 & -50 \\
\hline
\end{tabular}

The minimum convex radius of curvature $R_{\min }=+37 \mathrm{~km}$, according to the prediction may be accompanied by the land surface tilt of $\mathrm{T}=1.2 \mathrm{~mm} / \mathrm{m}$.

When the exploitation advances from south to north, the church tower will be the first to be influenced and should tilt towards the south, that is, should increase its inclination in this direction. The main body of the church building, on the other hand, will be subject to the impact consisting in the reduction of its tilt towards the north. As a result, the tower will incline by $T_{\max }=6 \mathrm{~mm} / \mathrm{m}$ to the south and basing of many years of experience and taking into consideration a significant weight and a high position of the center of gravity, one should assume that it can remain in this location, despite the fact that the terrain may return to its original horizontal position. On the other hand, the main body of the church building may, after the exploitation works had passed, return to its original position.

\subsection{General concept}

In order to counteract the different tilt of the tower and the main body, it is proposed to tie the building with tie rods according to the scheme shown in Fig. 8, where:

- tie rods (1) running along the length of the nave of the church,

- tie rod (2) running around the presbytery.

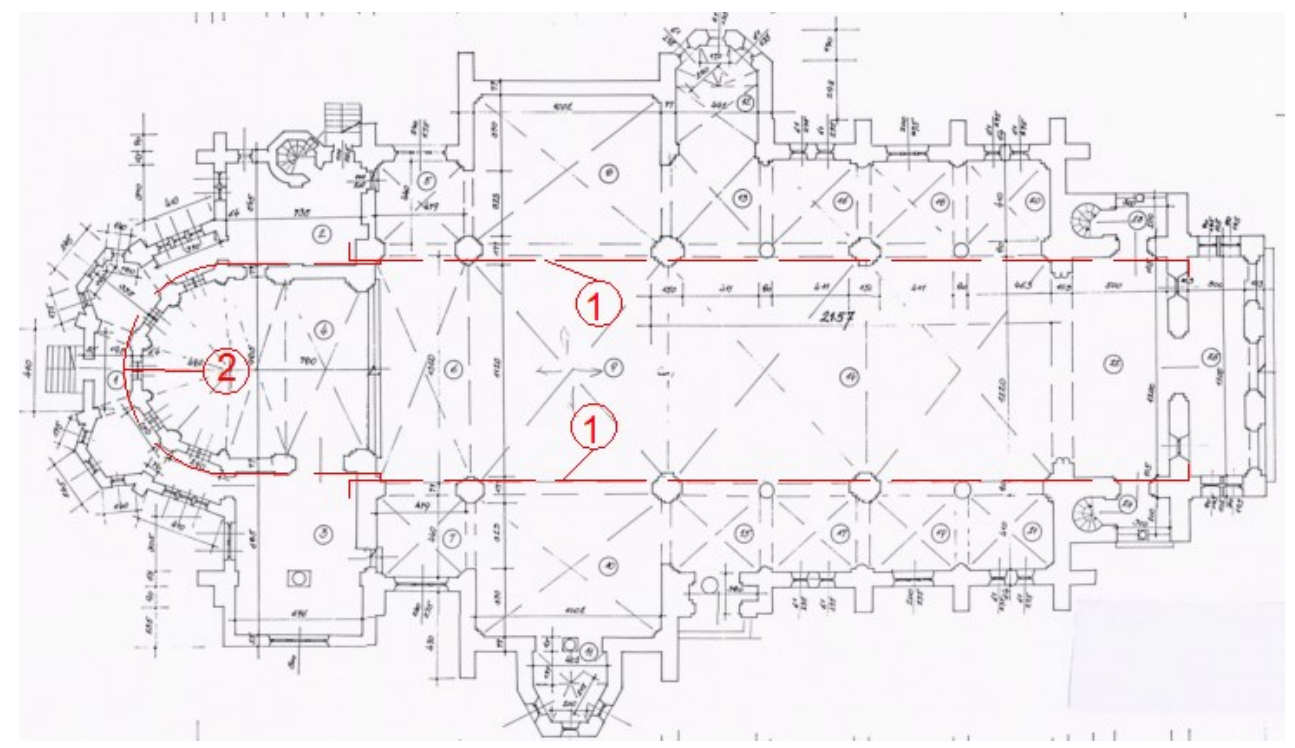

Fig. 8. Scheme of tie rods localizations in the church building - view in plan.

Tie rods (1) should be installed on the inside of the walls directly above the vault and under the roof at a height of approx. $15 \mathrm{~m}$ above the floor (Fig. 9). It should be emphasized that the center of gravity of the tower is located more or less at this height. Wherever possible, it is recommended to make each of the tie rods from two bars. Fixing of these tie rods will take place in the front wall of the tower and in the wall between the presbytery and the rest 
of the church. Following to the large length of the tie rods (approx. $40 \mathrm{~m}$ ), it was decided to rest them on the transverse walls of the church attic. Due to their length, the tie rods should be connected along their length using turnbuckles.

Tie rod (2) should also be anchored in the same wall and should run on the outside of the presbytery wall, at a similar height to anchors (1). Following to the shape of the presbytery wall, tie rod (2) shall be made from sections joined in a proper manner at the bends.

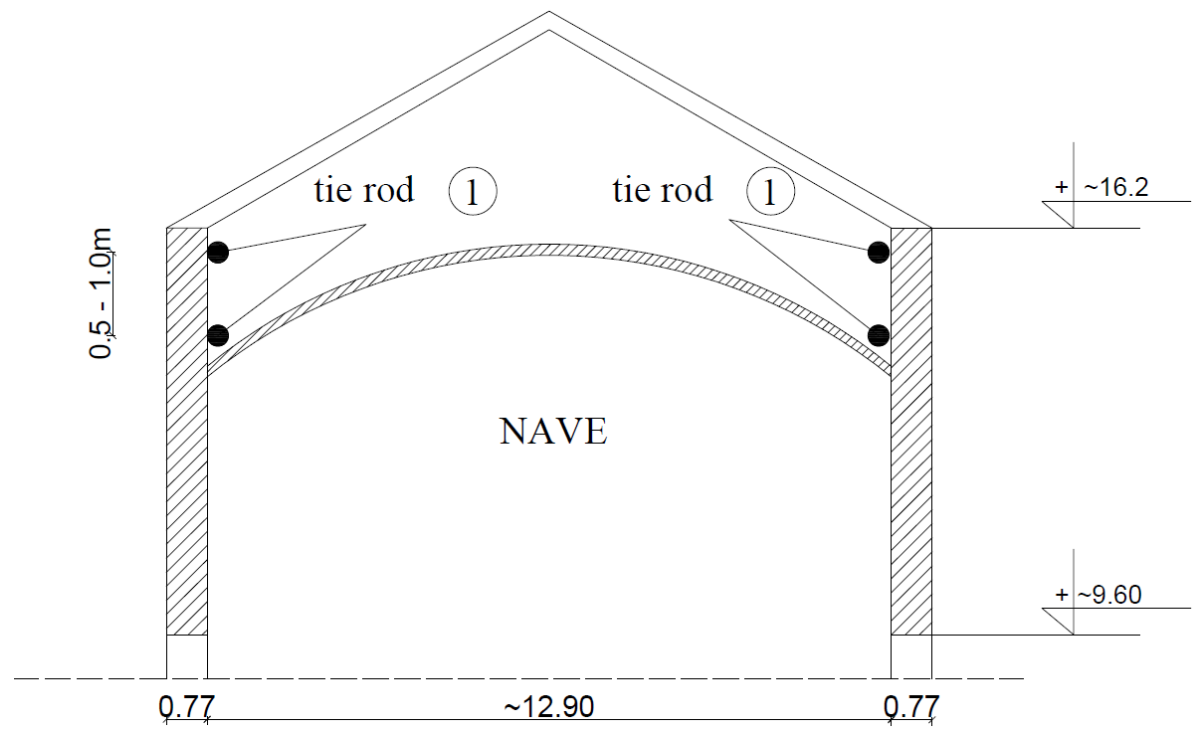

Fig. 9. A scheme of the church building strengthening - cross-section through the nave (dimensions in $\mathrm{m}$ ).

\subsection{Strengthening calculations (1) [4]}

\section{Testing of tie rods for impacts of $\Delta T_{b}=\mathbf{6 . 0 \%}$}

The dead load of the tower, the design change of the tilt and the tensile strength of steel wall were taken into account in the calculations. The calculation results imply that the required cross-section of anchors amounts to $15.32 \mathrm{~cm}^{2}$.

Tentatively, the application of four Ø25 rods with a cross-section area of $19.63 \mathrm{~cm}^{2}$.

Tie rod anchoring calculations:

The compressive strength and shear strength of the wall were taken into account in the calculations. The calculations results imply that the required surface of the anchor plate amounts to $1194.02 \mathrm{~cm}^{2}$, and the length of the edges of the anchor plate shall measure $117.03 \mathrm{~cm}$.

An anchor plate measuring $50 \mathrm{~cm} \times 30 \mathrm{~cm}=1500 \mathrm{~cm}^{2}$, whose aggregate edge length is $160 \mathrm{~cm}$, was adopted.

\section{Anchor plate thickness calculations}

The calculations incorporated the distance between the edge of the hole and the edge of the anchor plate, and the design load-bearing capacity of the bolt. The calculations results imply that the required thickness of the anchor plate is $11.7 \mathrm{~mm}$.

The anchor plate thickness of $14 \mathrm{~mm}$ was accepted. 
Test of tie rods for the impact of $\boldsymbol{R}_{\min }^{+}=37 \mathrm{~km}$ and the accompanying tilt $\boldsymbol{T}_{\boldsymbol{R}^{+}}=\mathbf{1 . 2 \%}$ In the case of $R^{+}{ }_{\min }$, there occurs also $\mathcal{E}^{+}{ }_{\max }=+2.2 \%$. The impact of $\mathcal{E}^{+}{ }_{\max }$ on the church building structure is not taken into consideration following to the fact that previous observations of the damage condition of the walls in the nave did not show any visible damage in the lower parts of the vault arches, which could have been caused by:

- the impact of the slab encompassing the outer walls of the church,

- reduction of the tensile stress in the lower parts of the walls by the influence of the curvature.

In such circumstances, the structure loading diagram should be assumed in a simplified manner as in Fig. 10.

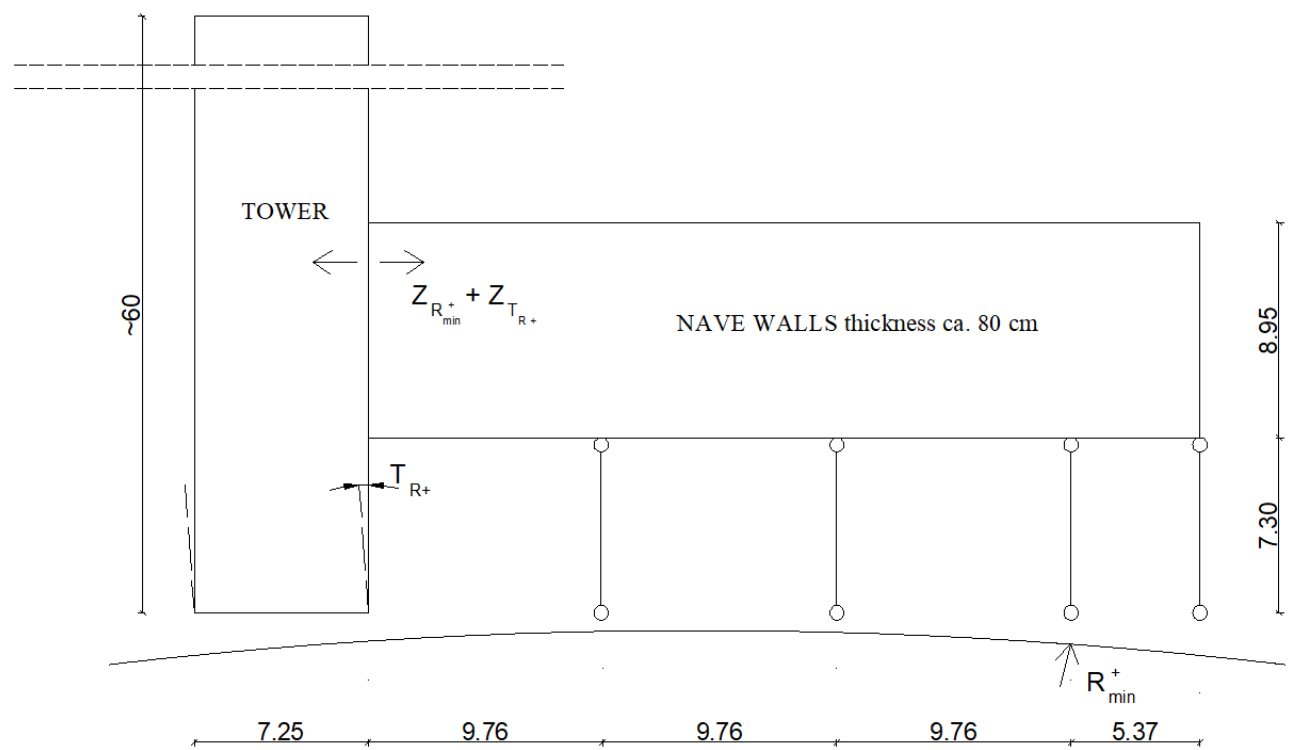

Fig. 10. The calculation scheme resulting from the simultaneous impact of $R^{+}$min and $T_{R^{+}}$ (dimensions in $\mathrm{m}$ )

Assuming, on the unfavourable side, that the bending radius of the church building is $\mathrm{R}=37 \mathrm{~km}$, it is possible to determine the bending moment per one wall:

Young's modulus of the wall: $E_{s c}=910 \mathrm{MPa}$

Moment of inertia: $I=(0.8 \cdot 8.953) / 12=47.79 \mathrm{~m}^{4}$

Design radius of curvature: $R_{d}=37000 / 1.7=21764 \mathrm{~m}$

It can be estimated that the moment acting from the curvature will not be greater than:

$M=E I / R=1.998 \mathrm{MN}$

Design inclination of the land surface: $T_{d}=1.5 \cdot 0.0012=0.0018$

The force per one tie rod:

- from the radius of curvature: $Z_{R \min +}=0.5 \cdot 1.998 /(0.67 \cdot 8.95)=0.167 \mathrm{MN}$

- from the land surface inclination: $Z_{T R+}=0.5 \cdot 36616.5 \cdot 0.0018=32.95 \mathrm{kN}$

The condition of $Z=167+33=200 \mathrm{kN}<0.5 \cdot 19.63 \cdot 21.5=211 \mathrm{kN}$ was maintained.

Elongation of tie rods

The anticipated elongation of tie rods amounts to $\Delta l=l \cdot \varepsilon=40 \mathrm{~m} \cdot 215 \mathrm{MPa} / 210 \mathrm{GPa} \approx 40 \mathrm{~mm}$

This impact of elongation can be eliminated to a certain extent with the use of turnbucles that connect the tie rods along their length. A similar method can be applied when dealing with changes in the tie rod length caused by temperature changes. 


\subsection{Calculations of tie rods (2) [4]}

On the basis of similar calculations as those performed for tie rods (1), a $\varnothing 22$ rod was accepted, with a cross-section area of $3.80 \mathrm{~cm}^{2}$.

\subsection{Utilisation of the concept and project implementation}

The proposed concept was utilised in the project involving protection of the said building. In addition to that, reinforcements of ribs of the nave in the form of reinforced concrete beams were designed and executed. Information about the project and the implementation of protective measures can be found in the paper [5].

\section{Summary}

The proposed method of strengthening the church building should prevent the tower from deflecting from the main body of the church and prevent the re-cracking of the vault, especially in the area near the tower. Relevant from the point of view of the continuous operation of the building and performance of the ongoing repairs of possible damages to the vaults, a platform is erected at the level their skewbacks.

During the passage of the mining basin under the church building, one cannot rule out cracking of the perimeter reinforced concrete slab, caused by horizontal deformations of the land surface $+\mathcal{E}$. There is practically no method to counteract this phenomenon. The only possible method to apply in this case is an immediate start of hammering out the concrete of the slab at the location of the crack, welding and re-concreting of this place.

\section{References}

1. M. Kawulok, Szkody górnicze w budownictwie (Instytut Techniki Budowlanej, Warszawa, 2015) [in Polish]

2. Z. Pająk, M. Wieczorek, The Polish Mining Review, 8, pp. 144-148 (2013) [in Polish]

3. M. Kawulok, L. Słowik, L. Chomacki, The Polish Mining Review, 12, pp. 25-31 (2016) [in Polish]

4. Document : Building Research Institute paper No 02219/17/Z00NZK (to be published) [in Polish]

5. Ł. Drobiec, T. Niemiec, M. Kawulok, L. Słowik, L. Chomacki, MATEC Web of Conf. ICSF Manuscript (2019) (to be published) 